\section{The Diagnosis and Treatment of Primary Osteoporosis According to Current Guidelines}

by Prof. Dr. med. Klaus M. Peters, Prof. Dr. med. Erika Baum in volume 33/2008

\section{Back Orthoses are Important}

The authors have successfully tackled a complex and difficult subject in a very compact format. However, we wish to correct some minor inaccuracies. On page 578, in the bottom left paragraph, they say: "Directed exercise programs can, at least, reduce the risk of falling, although the studies performed to date have included too few patients to demonstrate any resulting reduction of the fracture rate. Because fractures are relatively rare events, very large studies would be needed to demonstrate this." This statement cannot remain unchallenged: Kaptoge et al showed unequivocally in a prospective, population based, European wide study that in 2103 men and 2565 women, the event of a fall is of much greater importance for the development of an osteoporosis related fracture than, for example, reduced bone density (1). This has also been confirmed by a study of 2649 postmenopausal women, reported by Geusens et al (2).

Further, the authors omitted to mention the importance of back ortheses in the treatment of acute and chronic pain. The DVO guidelines of 2006 say: "After fractures, mobilization should be undertaken as soon as possible. To minimize pain, a spine stabilizing orthesis (...) is available (...) among others." Further, the authors say that in patients with chronic pain "(...) orthetic measures are helpful in stabilizing the posture and reducing pain. In addition to the acute fracture event, ortheses that exercise the muscles in the back are the preferred option."

DOl: 10.3238/arztebl.2009.0038a

\section{REFERENCES}

1. Kaptoge S, Benevolenskaya LI, Bhalla AK et al.: Low BMD is less predictive than reported falls for future limb fractures in women across Europe: results from the European Prospective Osteoporosis Study. Bone 2006; 38: 145-9.

2. Geusens P, Autier P, Boonen S, Vanhoof J, Declerck K, Raus J: The relationship among history of falls, osteoporosis, and fractures in postmenopausal women. Arch Phys Med Rehabil 83: 903-6.

3. Pfeifer M, Begerow B, Minne HW. Effects of a new spinal orthosis on posture, trunk strength and quality of life in women with postmenopausal osteoporosis. Am J Phys Med Rehabil 2004; 83: 177-86.

Dr. med. Michael Pfeifer

Prof. Dr. med. Helmut W. Minne

Institut für klinische Osteologie Gustav Pommer und Klinik

„DER FÜRSTENHOF“

Am Hylligen Born 7

31812 Bad Pyrmont, Germany

iko_pyrmont@t-online.de

\section{Conflict of interest statement}

The authors declare that no conflict of interest exists according to the guidelines of the International Committee of Medical Journal Editors.
Impairments Precede Fractures

In their CME article about the "... most common generalized disease of the skeleton ... [that] is markedly undertreated in Germany," the authors omitted to mention in the summary the necessary basic drug treatment with calcium and vitamin D3, which is mentioned only in the text, and in a complicated way that is not easy to remember. Also missing is the recommendation that in women older than 50 and men older than 60, body height should always be measured and the question about earlier measurement results should be asked.

This would enable confirmation of the suspected diagnosis in the early stages, and thus initiation of appropriate measures.

Measuring the waist circumference at the level of the umbilicus and taking blood pressure measurements may also help detect risk factors for cardiovascular disorders. Too often, we see patients who have received a prescription for an expensive bisphosphonate but have not received the necessary basic treatment.

With regard to clinical features: "Osteoporosis without fractures is an asymptomatic condition ... [it] becomes symptomatic by causing one or more fractures," this means waiting until problems manifest before making a diagnosis and initiating treatment. Osteoporosis of the spine causes problems even before the first fracture occurs. Hardly any patient will not report ongoing spinal complaints, mostly related to arthrosis in the small spinal joints, whose articular surfaces have a multitude of nociceptors. Osteoporotic spinal changes, cuneiform deformations of the vertebrae, kyphosis, and narrowing of the disc spaces all advance spondylarthrosis, the cause of 80 to $85 \%$ of all spinal problems. These can often be treated effectively with manual therapies, although unfortunately the effect is often transient.

DOl: 10.3238/arztebl.2009.0038b

Dr. med. Lothar L. Schute

Südring 56

63500 Seligenstadt, Germany

\section{Conflict of interest statement}

The authors declare that no conflict of interest exists according to the guidelines of the International Committee of Medical Journal Editors.

\section{Living With a Dilemma}

In principle it always makes sense to provide the colleagues at the coalface with a recommendation of how they might tackle the difficult pathology that is osteoporosis. Central to this are Professor Minne's words, that every case of osteoporosis requires treatment, but also recommendations from the US (NAMS) www guidelines.gov.

However, difficulties arise if only those patients are to be treated who have a $30 \%$ risk of vertebral or femoral fracture over the coming 10 years. For example, women aged 50 to 60 whose $T$ value is better than -4.0 will not receive treatment, although they are ill. Untreated 
osteoporosis is certain to advance, and these patients will end with a much lower $\mathrm{T}$ value over the following years. The treatment of osteoporosis is obviously rather costly if bisphosphonates are the only option under consideration. But the follow-on costs of osteoporosis related complications in Germany are in excess of five billion Euros per year. With regard to prophylaxis, the new recommendations of the International Menopause Society (www.imsociety.org) should be noted. I have personally been conducting DXA bone density scans since 1988 and unfortunately cannot confirm that treating of patients with $\mathrm{T}$ values of -4 yields sufficiently rapid improvements within a short time for a substantial reduction of the fracture risk to be expected. In heeding the DVO guidelines one has to live with the dilemma of conforming to the guideline and withholding treatment from patients and thus risking fractures that might have been prevented by early treatment.

DOI: 10.3238/arztebl.2009.0039a

\section{Dr. med. Bernhard Hörr}

Zehntgasse 1

73207 Plochingen, Germany

b.hoerr@hoerr-pet.de

Conflict of interest statement

The authors declare that no conflict of interest exists according to the guidelines of the International Committee of Medical Journal Editors.

\section{Unreliable in the Individual Case}

The interesting update provided by Baum and Peters is opposed by a more timely paradigm for defining osteoporosis: the consequence of the civilization related mechanical disuse of the skeleton by loads (1). The "gold standard" DXA is therefore not suitable for evaluating the risk of fractures because the deficiency is not primarily pathological. This also applies synonymously to the surplus of body fat which we carry with us. Systematic errors in DXA scanning can result in substantial over- or underestimation of the measured bone mineral content (2). The WHO definition was interpreted incorrectly. A pioneer of densitometry said in this regard (3): "But let it be clear that the World Health Organization $\mathrm{T}$ score criteria were proposed for use in epidemiological studies, for comparison between populations ... They were not intended for diagnosis or treatment decisions in individual cases."

Slim or anorexic individuals are often found to have a high "fracture risk" referring to DXA scans, whereas quantitative computed tomography (QCT) shows that the same vertebra shows normal resistance to fracture. Therefore, the T score is a doubtful basis for therapeutic decisions. Even an overwhelming wealth of data can not justify a "high level of evidence", since this evidence basis was misleadingly established and interpreted.

The pharmaceutical industry has almost exclusively used DXA scanning over the past 20 years to evaluate its osteoporosis drugs. The method is undoubtedly representative and valid in large sample sizes, but it is unreliable in the individual case scenario. The DVO guidelines acknowledge this fact only partly, provided that the method is used accordingly and the user is able to distinguish hidden individual measurement errors. In diabetes mellitus, a method to measure blood glucose level with a comparatively high inaccuracy would be dangerous.

DOl: 10.3238/arztebl.2009.0039b

\section{REFERENCES}

1. Frost HM, Schneider P, Schneider R: Osteoporosis a disease requiring treatment or osteopenia a physiologic state? - Behandlungsbedürftige Osteoporose oder physiologische Osteopenie? - WHO Definition im Gegensatz zum Utah Paradigma. Dtsch Med Wochenschr 2002; 127: 2570-4

2. Schneider P, Reiners Chr: Quantitative Bestimmung der Knochenmasse: heutiger Stand und Fallstricke der Methoden. Med Welt 1998; 49: 157-63.

3. Dequeker J: Bone densitometry is not a good predictor of hip fracture. BMJ 2001; 323: 795-9

Prof. Dr. med. Dipl.-Min. Peter Schneider

Universitätsklinikum

Klinik und Polokilinik für Nuklearmedizin

Josef-Schneider-Str. 2

97080 Würzburg, Germany

Conflict of interest statement

The author is a member of the organization REKO(Regionaler Expertenkreis

Osteoporose; regional expert circle for osteoporosis).

\section{In Reply:}

We welcome the volume of feedback to our CME article and thank all our critical readers for their correspondence. An update of the guideline that the article was based on is under way, and these comments will be included. With reference to Pfeiffer and Minne: The association between frequency of falls and fracture rates is uncontroversial and was taken into consideration in the guidelines as well as in our article. However, thus far there has been no proof that exercise programs lower the rate of fracture. The cited studies provide epidemiological data and not data on interventions. We certainly agree that further studies are needed-however, these would have to be financed out of the public purse since the pharmaceutical industry is not interested.

The Federal Ministry of Education and Research and the German Research Foundation, as well as other foundations, would have to be convinced that this is a worthy cause.

For reasons of space we did not discuss special measures such as ortheses or kyphoplasty/vertebroplasty. We thank Pfeiffer and Minne for pointing this out and agree with them.

With reference to Schute: The note about the probably necessary basic medication was placed at the start of the therapy chapter, to leave no reader in doubt about its necessity.

In the context of the health survey Checkup 35, documenting height and weight, in addition to other cardiovascular risk factors, is useful, but prompting for earlier height measurements will result in inaccuracies such that this variable has not been recommended as a screening instrument in the guideline. Non-specific back pain is common in the population and shows no association with reduced bone density without fractures, hence it does not constitute an indication for specific diagnostic 
testing. For recommendations on how to proceed, we refer to the guideline on back pain of the German Society of General Practice and Family Medicine (DEGAM).

With reference to Hörr: In patients who are close to the threshold for a specific treatment, the entire context should be carefully elucidated and decisions should be made jointly. The application of guidelines is not a hindrance to a well argued decision pertaining to an individual case. However, the costs and risks associated with long term medicalization should be borne in mind. If the fracture risk remains below 30\% for the following 10 years, the cost-benefit-risk relation quickly becomes unfavorable. In case of doubt, watchful waiting and intensifying the basic medication are an option. An imminent guideline on postmenopausal hormone therapy from the Deutsche Gesellschaft für Gynäkologie und Geburtshilfe (DGGG, the German Society for Obstetrics and Gynaecology) is due to evaluate the validity of the guidelines and recommendations cited by Hörr.
With reference to Schneider: Since almost all large therapeutic studies have been conducted on the basis of DXA measurements and only few data are available on therapeutic effects with other measuring methods, the evidence based recommendations can be furnished only with DXA values. Theoretical considerations are not getting us anywhere further in this context. In the individual case-for example, in a patient prone to unexplained fractures - the use of other measuring methods is wholly justified, however. D0l: 10.3238/arztebl.2009.0040

\section{REFERENCES}

1. Becker A, Niebling W, Chenot JF, Kochen MM: Degam-Leitlinie Kreuzschmerzen. 2006 Omikron publishing Düsseldorf.

http://www.degam.de/leitlinien/LL_Kreuz_Internet_druck.pdf

Prof. Dr. med. Klaus M. Peters

Rhein-Sieg-Klinik

Höhenstr. 30

51588 Nümbrecht, Germany

kpeters@dbkg.de

Conflict of interest statement

The authors declare that no conflict of interest exists according to the guidelines of the International Committee of Medical Journal Editors. 